\title{
Sensation of the autologous reconstructed breast improves quality of life: a pilot study
}

\author{
Anouk J. M. Cornelissen ${ }^{1}$ (1) - Jop Beugels ${ }^{1}$ - Sander M. J. van Kuijk ${ }^{2}$ • \\ Esther M. Heuts ${ }^{3} \cdot$ Shai M. Rozen $^{4} \cdot$ Aldona J. Spiegel $^{5}$. \\ René R. W. J. van der Hulst ${ }^{1}$ - Stefania M. H. Tuinder ${ }^{1}$
}

Received: 1 June 2017 / Accepted: 16 October 2017 / Published online: 25 October 2017

(C) The Author(s) 2017. This article is an open access publication

\begin{abstract}
Purpose The number of breast cancer survivors continues to grow. Due to refinements in operating techniques, autologous breast reconstruction has become part of standard care. Impaired sensation remains a debilitating side effect with a significant impact on the quality of life. Microsurgical nerve coaptation of a sensory nerve has the potential to improve sensation of the reconstructed breast. This study investigates the effect of improved sensation of the reconstructed breast on the quality of life in breast cancer survivors.

Methods A retrospective cohort study was performed in the Maastricht University Medical Center. Patients undergoing a DIEP flap breast reconstruction between January 2015 and January 2016 were included. The primary outcome was quality of life (BREAST-Q domain 'physical well-being of the chest'). The Semmes-Weinstein monofilaments were
\end{abstract}

Stefania M. H. Tuinder

s.tuinder@mumc.nl

1 Department of Plastic Surgery, Maastricht University Medical Center +, P. Debyelaan 25, 6229 HX Maastricht, The Netherlands

2 Department of Clinical Epidemiology and Medical Technology Assessment, Maastricht University Medical Center +, P. Debyelaan 25, 6229 HX Maastricht, The Netherlands

3 Department of Surgery, Maastricht University Medical Center +, P. Debyelaan 25, 6229 HX Maastricht, The Netherlands

4 Department of Plastic and Reconstructive Surgery, University of Texas Southwestern Medical Center, 1801 Inwood Road, Dallas, TX 75390, USA

5 Division of Plastic Surgery, Houston Methodist Hospital, 6565 Fannin St, Houston, TX 77030, USA used for objective sensation measurement of the reconstructed breast(s).

Results Eighteen patients with and 14 patients without nerve coaptation responded. Nipple reconstruction was the only characteristic that differed statistically significant between both groups $(p=0.04)$. The BREAST-Q score for the domain physical well-being of the chest was $77.89 \pm 18.89$ on average in patients with nerve coaptation and $66.21 \pm 18.26$ in patients without nerve coaptation $(p=0.09)$. Linear regression showed a statistically significant relation between objectively measured sensation and BREAST-Q score for the domain physical well-being of the chest with a regression coefficient of $-13.17 \pm 3.61$ $(p<0.01)$.

Conclusions Improved sensation in the autologous reconstructed breast, with the addition of microsurgical nerve coaptation, has a statistical significant positive impact on the quality of life in breast cancer survivors according to the BREAST-Q.

Keywords Breast reconstruction - Sensation - Quality of Life $\cdot$ Neurotisation $\cdot$ Nerve coaptation

\section{Purpose}

Although the incidence of breast cancer continues to grow, so do survival rates $[1,2]$. Thus, the quality of life of breast cancer survivors has become of great importance. Although breast conservation therapy continues to be a major part of breast cancer treatment, mastectomy numbers continue to grow. In addition, more prophylactic (contralateral) mastectomies are being performed [3-6]. Approximately 40\% of patients with invasive breast cancer and $33 \%$ of patients with ductal carcinoma in situ undergo mastectomy [7-9]. 
A mastectomy has a negative impact on body image, which in women is partially determined by a sense of femininity and attractiveness $[10,11]$. Fortunately, breast reconstruction has shown to improve body image and quality of life [12-15]. The number of women undergoing breast reconstruction with either autologous tissue transfer or implants, is generally low and varies from 5 to $30 \%$ [16]. Preoperative referral to a plastic surgeon might have an influence on these numbers $[17,18]$. Autologous reconstruction (41\% of breast reconstructions) has shown superior results on quality of life if compared to implant reconstruction $(61 \%$ of breast reconstructions) [19]. Due to refinements in operating techniques, autologous breast reconstruction has become part of standard breast cancer care.

Impaired sensation in the transposed skin and surrounding skin envelope after autologous breast reconstruction remains a debilitating side effect with a negative impact on the quality of life [20]. Sensation of the breast consists of different aspects: temperature, tactile, pain and erogenous sensation. Cases of burns or injuries of the insensitive autologous reconstructed breast have been described previously [21,22], emphasizing the protective function of breast sensation and the importance of restoration of pain and temperature sensation in the reconstructed breast. Emotional reasons such as the need to feel feminine and sexually attractive again have been described in previous studies as decisive factors to opt for an autologous breast reconstruction. Furthermore, the question 'does your reconstructed breast feel like your own?', seems to be the most important determinant in patient satisfaction [23, 24]. It is questionable whether these goals can be achieved by reconstructing a mound of soft-tissue, although aesthetically pleasing, without any sensation. We believe restoring tactile sensation of the reconstructed breast enables women to experience their breast like 'of their own'. This hypothesis is supported by a recent article in the New York Times that also emphasizes the importance of this topic to society [25]. This explains the recent trend to perform a microsurgical nerve coaptation of the sensory nerve of the DIEP flap to the 2nd or 3rd intercostal nerve. This addition to the technique has shown to improve sensation of the reconstructed breast [26-31].

In this study, the effect of sensory nerve coaptation in patients with a DIEP flap breast reconstruction on the quality of life as measured by the BREAST-Q when compared to standard reconstruction without nerve coaptation was evaluated for the first time.

\section{Methods}

This study was conducted according to the STROBE guidelines and was approved by the medical ethical committee of the Maastricht University Medical Center [32].

\section{Patient population}

We performed a retrospective cohort study in the Maastricht University Medical Center in Maastricht, the Netherlands. Participants included all consecutive patients, who underwent a DIEP flap breast reconstruction with or without nerve coaptation, between January 2015 and January 2016 in our center. Because of the retrospective design of this study, blinding patients with respect to sensory nerve was not possible. Medical records of 143 potential candidates were screened for a follow-up appointment at the Maastricht University Medical Center in January 2017 to obtain informed consent and to measure sensation of the reconstructed breast(s). The BREAST-Q and five additional questions, specifically about sensation in the reconstructed breast(s), with a self-addressed postage-paid return envelope were sent to consenting patients.

\section{Data collection}

A chart review of all included participants was performed to compile data on the following patient characteristics: nerve coaptation, age, BMI, (neo) adjuvant chemo- and/or radiotherapy, reconstructive timing (immediate versus delayed), unilateral versus bilateral reconstruction, reason for mastectomy (prophylactic versus malignancy), complications, stage of reconstruction (nipple reconstruction already performed or not yet), and follow-up.

Patients were invited to complete the BREAST-Q questionnaire (Dutch for the Netherlands, reconstruction module) and five additional questions about breast sensation in particular (Table 1). If Dutch was their second language, an interpreter was suggested. The raw BREAST-Q scores were converted into domain scores using the QScore software programme (Memorial Sloan Kettering Cancer Institute, New York). The domain scores range from 0 to 100 per domain. A higher score indicates a better quality of life. Patients were asked to complete the domains that are likely to be influenced by sensation of the breast: physical well-being of the chest, psychosocial well-being, sexual well-being, satisfaction with breasts and satisfaction with outcome. These domains were used as separate outcome variables, as a total BREAST-Q score cannot be computed. The primary outcome was defined as the domain physical well-being of the chest, since we deemed it the most important quality of life measure related to sensation after breast reconstruction. The remaining domains and the five additional questions were considered as secondary outcomes. The five additional questions were scored on a 5-point Likert-type scale which was later dichotomized (Table 1).

The Semmes-Weinstein monofilaments were used for sensation measurement of the reconstructed breast(s) [33]. The researcher was blinded for the treatment group of the 
Table 1 Additional questions concerning sensation of the reconstructed breast, scored on a 5-point Likert scale with dichotomizing process and codes under each question
1. Do you have sensation in your reconstructed breast(s)?

Very much Much A bit Little Very little

Dichotomized: very much - a bit $=1$, little - very little $=0$

2. Does the sensation in your reconstructed breast resemble the sensation of your healthy breast before operation?

The same Almost the same Similar A bit similar Totally different

Dichotomized: the same - a bit similar $=1$, totally different $=0$

3. How important do you find sensation in your breast?

Very important Important Neutral Not very important Not important

Dichotomized: very important - important $=1$, neutral - not important $=0$

4. Do you find it important that your reconstructed breast has sensation?

Very important Important Neutral Not very important Not important

Dichotomized: very important - important $=1$, neutral - not important $=0$

5 . How important is the return of sensation in your reconstructed breast for your overall satisfaction with the result of the operation?

Very important Important Neutral Not very important Not important

Dichotomized: very important - important $=1$, neutral - not important $=0$ patient (with or without nerve coaptation). Each monofilament value represents the logarithm of the force in milligrams required to bend the monofilament. Therefore, a thinner monofilament requires less pressure to bend and, if felt by the patient, represents improved one point static discrimination compared to a patient who is not able to feel it. Perpendicular pressure was applied to the same spot until monofilament bending was noted each time for a duration of $1.5 \mathrm{~s}$, three times in succession, with intervals of $1.5 \mathrm{~s}$. Testing started with the thinnest monofilament and progressed to monofilaments of increasing pressure until touch was identified in at least one out of three times by the patient. Patients were asked to lay on their back and close their eyes, measurements took place in a quiet room. The different sites were tested in a random sequence to ensure touch at a particular site could not be predicted [24].

The areas to be measured were predefined by anatomical references; nine areas were tested in each breast. The breasts were divided into four quadrants by two lines; a vertical line was drawn from mid clavicle to the nipple; a horizontal line was drawn perpendicular to the first line at the nipple level. A circle was drawn around the breast tissue defined by the inframammary and supramammary crease which were determined by using the manoeuvre described by Marchac and de Olarte [34]. The breast was displaced cranially, caudally, medially, and laterally to define the respective borders of the breast. Thus, a circle with four quadrants was created with the nipple as it is centre. Each circle quadrant was bisected with a line drawn at $45^{\circ}$. Sensation was measured on the middle of each line and in the areola in each quadrant, and on the nipple (Fig. 1).

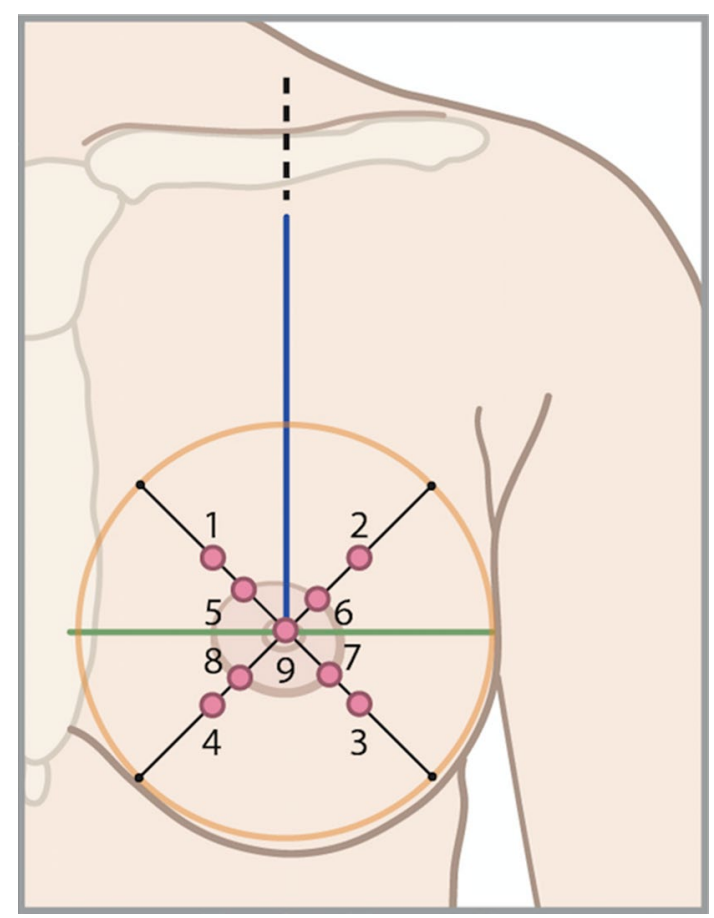

Fig. 1 Anatomical landmarks of the breast for the nine sensation measurement points. The breasts were divided into four quadrants by two lines; line 1 (blue) was drawn from the mid of the clavicle to the nipple; line 2 (green) was drawn perpendicular on line 1 . A circle (orange) was drawn around the breast tissue defined by the inframammary and supramammary crease. In each quadrant, a line (black) was drawn at $45^{\circ}$. On the middle of these four lines, sensation was measured. In addition, measurements were done on the areola in each quadrant 


\section{Operating technique: nerve coaptation}

A nerve coaptation of the 2 nd or 3 rd intercostal nerve to a sensory nerve of the DIEP flap was performed [35]. Nerve coaptation was performed under the microscope using two epineural stitches with 10-0 nylon. To fix the nerve, some tissue glue was added after coaptation was completed. On average, this extended the operation time by $15 \mathrm{~min}$ with no increased risk of complications. Neuropathic pain was not observed.

\section{Statistical analysis}

As this was a pilot study, we did not compute the necessary sample size based on ample power to detect clinically relevant differences in BREAST-Q domain scores. Information on what differences can be regarded as clinically relevant, as well as measures of spread, were not available. Therefore, we included all records that were available at the time which fit the inclusion and exclusion criteria, to be able to estimate differences between the two groups as precisely as possible.

Baseline characteristics were compared between groups: DIEP-flap breast reconstruction with nerve coaptation (group 1) and DIEP-flap breast reconstruction without nerve coaptation (group 2). Continuous variables were reported as mean with standard deviation or median with range, depending on the distribution of the variables. Categorical variables were reported as absolute numbers and proportions. Continuous variables were compared using the independent $t$ test or the Mann-Whitney $U$ test, and categorical variables were assessed using $\chi^{2}$ test or Fisher's exact test.

Sensation measurements of the breast(s) were averaged in order to create one value per patient. An independent samples $t$ test was used to evaluate differences between both groups in mean monofilament value and mean BREAST-Q scores per domain. In addition, both simple and multiple (i.e. unadjusted and adjusted) linear regressions were used to estimate the crude and adjusted associations between objectively measured sensation and the BREAST-Q score domains. The adjusted regression coefficient was corrected for baseline characteristics that differed statistically significant between groups.

The five additional questions were analysed using both simple and multiple logistic regressions and were reported as odds ratios (OR) with a $95 \%$ confidence interval (CI).

A $p$ value $<0.05$ was considered to be statistically significant. All analyses were performed using IBM SPSS (Released 2013. Version 24.0. Armonk, NY: IBM Corp).

\section{Results}

\section{Response rate}

In total, 44 patients of 143 screened records were eligible. Eighteen patients with and 14 patients without nerve coaptation responded. This resulted in an overall response rate of $73 \%$ (32 out of 44). (Fig 2).

\section{Patient characteristics}

Patient characteristics between the group of patients with and the group of patients without nerve coaptation were compared (Table 2). The variables age, BMI, chemotherapy, radiotherapy, reconstructive timing (immediate versus delayed), unilateral versus bilateral breast reconstruction, reason for mastectomy (prophylactic versus malignancy), and complications did not differ significantly between groups. However, stage of reconstruction (nipple reconstruction already performed or not yet) differed significantly between these two groups $(p=0.04)$. In the group of patients without nerve coaptation, $92.9 \%$ already underwent a nipple reconstruction compared to $44.4 \%$ of patients in the group of patients with nerve coaptation.

\section{Sensory and quality of life results}

The mean monofilament value in patients who underwent a breast reconstruction with nerve coaptation was lower 4.35 than in patients without nerve coaptation 5.30, which indicates better sensation in patients with nerve coaptation. Despite our small sample size, this mean difference was statistically significant $p<0.01$. (Table 3 ) The mean score of the BREAST-Q domain physical well-being of the chest was also compared between both groups: the mean score of patients with nerve coaptation was higher (77.89) than without nerve coaptation (66.21) ( $p=0.09)$, which suggests a higher quality of life in patients with nerve coaptation. (Table 3).

The relation between objectively measured sensation and BREAST-Q score for the domain physical well-being of the chest was explored in a linear regression model and showed a statistically significant correlation $(p<0.01)$ with a crude regression coefficient of -13.17 and a $R^{2}$ of 0.31 (Fig. 3; Table 4). The adjusted regression coefficients were $-11.47 \pm 2.53$ for the variable monofilament with a $R^{2}$ of $0.40(p<0.01)$. (Table 4$)$ The results of the crude and adjusted regression coefficients of the secondary outcome domains of the BREAST-Q of this study are shown in Table 4.

The relation between objectively measured sensation and BREAST-Q score for the domain physical well-being of the chest was also explored for primary and secondary breast 


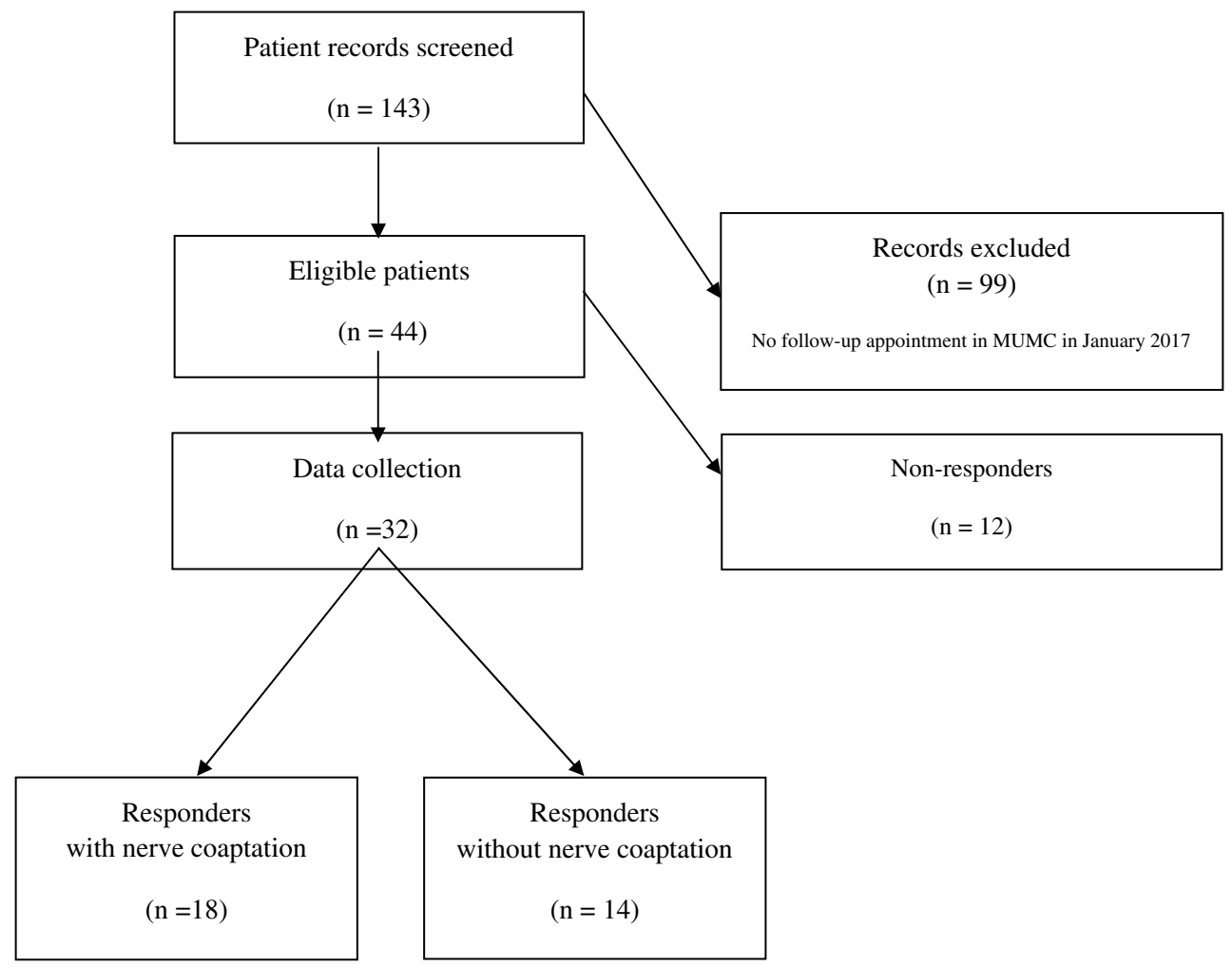

Fig. 2 Patient enrolment flow chart

Table 2 Demographic characteristics of included patients

\begin{tabular}{|c|c|c|c|}
\hline Variable & $\begin{array}{l}\text { Nerve coaptation } \\
(n=18)\end{array}$ & $\begin{array}{l}\text { No nerve coaptation } \\
(n=14)\end{array}$ & $p$ value (2-sided) \\
\hline Age at operation, mean in years $\pm \mathrm{SD}$ & $47.11 \pm 9.2$ & $47.71 \pm 4.73$ & 0.825 \\
\hline $\mathrm{BMI}$, mean in $\mathrm{kg} / \mathrm{m}^{2} \pm \mathrm{SD}$ & $26.44 \pm 2.77$ & $28.21 \pm 3.04$ & 0.096 \\
\hline \multicolumn{4}{|l|}{ Chemotherapy, \% } \\
\hline Previous chemotherapy & 44.4 & 57.1 & \multirow[t]{2}{*}{0.476} \\
\hline No previous chemotherapy & 55.6 & 44.9 & \\
\hline \multicolumn{4}{|l|}{ Radiotherapy, \% } \\
\hline Previous radiotherapy & 22.2 & 14.3 & \multirow[t]{2}{*}{0.672} \\
\hline No previous radiotherapy & 77.8 & 85.7 & \\
\hline \multicolumn{4}{|l|}{ Reconstructive timing, $\%$} \\
\hline Immediate & 61.1 & 42.9 & \multirow[t]{2}{*}{0.305} \\
\hline Delayed & 38.9 & 57.1 & \\
\hline \multicolumn{4}{|l|}{ Unilateral versus bilateral, $\%$} \\
\hline Unilateral & 27.8 & 42.9 & \multirow[t]{2}{*}{0.465} \\
\hline Bilateral & 72.2 & 57.1 & \\
\hline \multicolumn{4}{|l|}{ Reason mastectomy, \% } \\
\hline Malignancy & 66.7 & 42.9 & \multirow[t]{2}{*}{0.178} \\
\hline Prophylactic & 33.3 & 57.1 & \\
\hline Complication, $\%$ & 33.3 & 14.3 & 0.412 \\
\hline \multicolumn{4}{|l|}{ Stage of reconstruction, $\%$} \\
\hline Nipple reconstruction & 44.4 & 92.9 & \multirow[t]{2}{*}{$0.04 *$} \\
\hline No nipple reconstruction & 55.6 & 7.1 & \\
\hline Follow-up in months \pm SD & $16.13 \pm 3.24$ & $14.76 \pm 4.30$ & 0.33 \\
\hline
\end{tabular}

*Statistical significant results 
Table 3 Mean monofilament value and BREAST-Q score compared between patients with and without nerve coaptation

\begin{tabular}{lllc}
\hline & Nerve coaptation $(n=18)$ & No nerve coaptation $(n=14)$ & $p$ value (2-sided) \\
\hline Monofilament value & $4.35[4.00-4.69]$ & $5.30[4.94-5.66]$ & $<0.01$ \\
Physical well-being chest & $77.89[68.51-87.27]$ & $66.21[55.67-76.76]$ & 0.09 \\
\hline
\end{tabular}

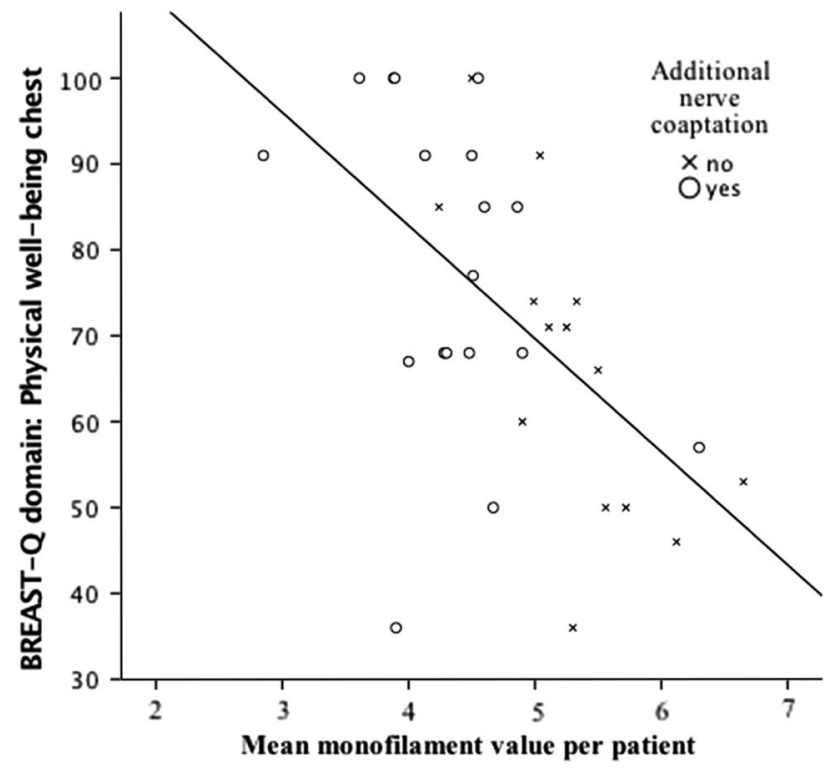

Fig. 3 Linear regression: Relationship between quality of life and sensation in DIEP reconstructed breast. $y$-axis represents the value of the BREAST-Q domain physical well-being of the chest, values range from 1 to 100: a higher value represents a higher patient satisfaction. $x$-axis represents a mean monofilament value, which was calculated per patient, if a patient underwent a reconstruction bilaterally one mean value for both breasts was calculated. A scatterplot in which the circles represent the patients with nerve coaptation and the crosses represent patients without nerve coaptation is shown. The black line is the linear regression with a regression coefficient of $-13.17 \pm 3.61$ and a $R^{2}$ of $0.31 \pm 16.26(p<0.01)$

reconstruction separately. Regression coefficient, $R^{2}$ and $p$ value are, respectively, given for primary breast reconstruction: $-14.72,0.27$ and 0.03 , and for secondary breast reconstruction: $-14.07,0.42$ and $<0.01$.
A negative association of the monofilament value with the additional question 1 'Do you have sensation in your reconstructed breast( $(s)$ ?' was observed (OR 0.24, 95\% CI 0.06-0.89). This suggests that a higher monofilament value, which represents less sensation, is statistically significant associated with answering negatively on this question.

A negative association of monofilament value with additional question 2 'Does the sensation in your reconstructed breast resemble the sensation of your healthy breast before operation?' was also observed (OR $0.10,95 \%$ CI 0.02-0.54). This indicates a higher monofilament value to be statistically significant associated with a negative answer on this question.

The remaining additional questions showed the following results: $64.52 \%$ of the respondents indicated to find breast sensation important to very important, $58.06 \%$ indicated that finding sensation in the reconstructed breast important was very important and $38.71 \%$ indicated that return of sensation in the reconstructed breast was important to very important for their overall satisfaction with the operation.

\section{Discussion}

Breast reconstruction techniques have evolved greatly over the past decade, from focussing on survival of the transplanted tissue to minimizing morbidity and improving aesthetical outcome. Despite the efforts to recreate a natural looking breast, restoring sensation has been rather disregarded. Yet, we strongly believe that increased sensation of the reconstructed breast improves quality of life in breast cancer survivors. A study by Temple et al. in 2009 confirmed that innervation of the free TRAM flap breast reconstruction

Table. 4 Crude and adjusted linear regression coefficients of primary and secondary outcome domains of the BREAST-Q in relationship to objectively measured sensation (mean monofilament value)

\begin{tabular}{|c|c|c|c|c|c|c|c|}
\hline \multirow[t]{2}{*}{ Independent } & \multirow[t]{2}{*}{ Dependent } & \multicolumn{3}{|l|}{ Crude } & \multicolumn{3}{|c|}{ Adjusted $^{\mathrm{a}}$} \\
\hline & & Coeff & CI & $p$ value & Coeff & $\mathrm{CI}$ & $p$ value (2-sided) \\
\hline Physical well-being chest & Mean monofilament value & -13.17 & $-20.53--5.81$ & $<0.01$ & -11.47 & $-18.68--4.26$ & $<0.01$ \\
\hline Satisfaction with breast & Mean monofilament value & -2.20 & $-10.62-4.79$ & 0.45 & -2.33 & $-10.34-5.70$ & 0.56 \\
\hline Satisfaction with outcome & Mean monofilament value & -8.02 & $-17.74-1.71$ & 0.10 & -6.89 & $-16.73-2.95$ & 0.16 \\
\hline Psychosocial well-being & Mean monofilament value & 0.77 & $-8.52-10.06$ & 0.17 & 1.19 & $-8.52-10.90$ & 0.80 \\
\hline Sexual well-being & Mean monofilament value & 0.66 & $-10.07-11.39$ & 0.90 & 2.29 & $-8.50-13.08$ & 0.67 \\
\hline
\end{tabular}

coeff regression coefficient, $C I$ confidence interval

${ }^{a}$ Adjusted for stage of reconstruction (nipple reconstruction already performed or not yet) 
improves quality of life [20]. However, Temple et al. used general quality of life questionnaires to detect differences in quality of life thanks to improved breast sensation: the Medical Outcomes Study 36-Item Short Form, the Body Image after Breast Cancer Questionnaire and the Functional Assessment of Cancer Therapy-Breast quality-oflife. Validity of these instruments can be questioned. These instruments might be too general to evaluate quality of life related to breast sensation. As was suggested by Alderman and Chung in a discussion on the article by Temple et al., it is possible that factors other than breast sensation have influenced the results [36]. In this study, a more specific questionnaire (BREAST-Q) was used that was validated specifically among patients who underwent a mastectomy and a DIEP-flap breast reconstruction.

Our data showed a statistical significant improvement in objectively measured sensation of the reconstructed breast in the group of patients with nerve coaptation when compared to the group of patients without nerve coaptation. This is supported by many other studies [26-31]. However, an improvement in objectively measured sensation, like pressure sensitivity, does not unequivocally entail that the reconstructed breast feels more like a natural breast. The qualitative aspect of sensation is ignored if only objective sensation measurements are used; therefore, patient-reported outcomes are crucial. This is especially true with the rise in breast cancer survivors and the corresponding increased focus on patients' quality of life as suggested by Wommack and Spiegel [37]. Moreover, the current health care economic environment mandates patient-reported outcomes and health-related quality of life research to justify added expense of increasingly complex surgical procedures.

This is the first study that measures quality of life using a questionnaire, which is specifically validated in patients who underwent a DIEP flap breast reconstruction (BREAST-Q), to evaluate the influence of breast sensation on the quality of life [38]. The domain physical well-being of the chest was chosen as primary outcome in this study since improved breast sensation will most likely influence this domain. The primary outcome of the current study, BREAST-Q domain physical well-being of the chest, was compared between patients with and without nerve coaptation. On average, the BREAST-Q score for the domain physical well-being of the chest was 11.68 points higher for the group with nerve coaptation. The smallest clinically significant difference of the BREAST-Q score is not yet defined. A study of the subjective significance to patients of changes in quality of life scores by the developers of the BREAST-Q, Pusic et al., suggests that a mean difference of 5-10 on the multi-item scales is perceived as a small clinical difference, $10-20$ as a moderate and greater than 20 as a clinically important difference. Therefore, this difference might be considered moderately clinically relevant; however, we observed no statistically significant differences. The relatively small sample size of this pilot study is the likely cause of insufficient statistical power to detect clinically meaningful differences of this magnitude.

An additional linear regression model comparing objectively measured sensation with BREAST-Q score for the domain physical well-being of the chest was performed. This showed a highly statistically significant association between improved sensation and increased BREAST-Q score for the domain physical well-being of the chest, even if we corrected for statistical significant differences in baseline characteristics. Stage of reconstruction (nipple reconstruction already performed or not yet) was the only statistical significant baseline characteristic between both groups, which differed in favour of the group without nerve coaptation. Therefore, the positive effect on quality of life, thanks to additional nerve coaptation, might be rather underestimated.

This linear regression model was also studied for primary and secondary breast reconstructions separately because the surface of the transposed skin is usually much bigger in secondary breast reconstructions. Therefore, we expected the effect to be higher in patients who underwent a secondary breast reconstruction. This hypothesis might be confirmed by our analysis: a larger proportion of difference in BREAST-Q score can be explained by objective improvement of sensation for secondary breast reconstruction (42\%) if compared to primary breast reconstruction $(27 \%)$ and the statistical significance was more profound for secondary $(p=0.009)$ than for primary ( $p=0.032)$ breast reconstruction.

Statistically significant regression coefficients of all the above models showed that a perceptible difference in the quality of life of breast cancer survivors can be explained by improved sensation of the DIEP flap reconstructed breast. This suggests that focussing on improved sensation of the reconstructed breast is worth the effort. A note of caution is due here since purposely blinding of patients could not be carried out, due to the retrospective design of this study. This is an important issue for future research. Further studies, which take this possible bias into account, will need to be undertaken, e.g. a larger randomized double-blinded prospective study would provide more data on this issue.

The BREAST-Q domain physical well-being of the chest contains 16 items and only eight items explore sensation of the reconstructed breast. Of those, only one question investigates the effect of positive sensation in the reconstructed breast. Additionally, the domain satisfaction with breasts contains two questions on breast sensation; however, this domain contains 25 items. We believe the domain of physical well-being of the chest to be more specific for breast sensation. Unfortunately, BREAST-Q questions were not validated to be analysed separately.

Even though the BREAST-Q (reconstruction module) is currently the most specific validated instrument to measure 
quality of life in breast cancer patients who underwent an autologous breast reconstruction, it is still not developed to measure differences in quality of life specifically related to improved sensation. Development and validation of a specific questionnaire could be of great value. Previous publications showed the question 'does your reconstructed breast feel like your own?', to be the most important determinant in patient satisfaction [23, 24]. However, these studies did not use validated questionnaires. In the current study, the group of patients with nerve coaptation were statistically more likely to answer positively on the question 'Does the sensation in your reconstructed breast resemble the sensation of your healthy breast before operation?'. This might indicate a higher patient satisfaction. Furthermore, $64.52 \%$ of the respondents indicated to find breast sensation important to very important.

In this study, five patients who received a bilateral DIEPflap breast reconstruction with only unilateral nerve coaptation, due to anatomical variations or technical difficulties, were excluded from the analysis, because BREAST-Q scores are analysed per patients rather than per flap. However, these patients can perfectly compare the results of a DIEPflap breast reconstruction with and without nerve coaptation. Telephone interviews with these five patients taught us that these women experienced the reconstructed breast with nerve coaptation to feel less numb. Also, the reconstructed breast with nerve coaptation felt more like their own. This again shows the importance of sensation of the reconstructed breast; however, we are aware of the fact that these are empirical observations.

\section{Conclusions}

This pilot study suggests that improved sensation in the autologous reconstructed breast, via an additional microsurgical nerve coaptation, has a statistical significant positive impact on the quality of life in breast cancer survivors according to the BREAST-Q. Therefore, nerve coaptation has a direct impact on patient outcomes and should be considered a useful addition to the surgical technique of autologous breast reconstruction.

Funding No funding was received for this study.

\section{Compliance with ethical standards}

Conflict of interest The authors declare that they have no conflict of interest.

Ethical approval This study was conducted according to the accepted principles of ethical and professional conduct. In accordance with the ethical standards as laid down in the 1964 Declaration of Helsinki and its later amendments.
Informed consent Informed consent was obtained from all individual patients included in the study.

Open Access This article is distributed under the terms of the Creative Commons Attribution 4.0 International License (http://creativecommons.org/licenses/by/4.0/), which permits unrestricted use, distribution, and reproduction in any medium, provided you give appropriate credit to the original author(s) and the source, provide a link to the Creative Commons license, and indicate if changes were made.

\section{References}

1. Youlden DR, Cramb SM, Dunn NA, Muller JM, Pyke CM, Baade PD (2012) The descriptive epidemiology of female breast cancer: an international comparison of screening, incidence, survival and mortality. Cancer Epidemiol 36(3):237-248. doi:10.1016/j. canep.2012.02.007

2. van der Waal D, Verbeek AL, den Heeten GJ, Ripping TM, TjanHeijnen VC, Broeders MJ (2015) Breast cancer diagnosis and death in the Netherlands: a changing burden. Eur J Publ Health 25(2):320-324. doi:10.1093/eurpub/cku088

3. Pesce CE, Liederbach E, Czechura T, Winchester DJ, Yao K (2014) Changing surgical trends in young patients with early stage breast cancer, 2003 to 2010: a report from the National Cancer Data Base. J Am Coll Surg 219(1):19-28. doi:10.1016/j. jamcollsurg.2014.03.043

4. Dasari CR, Gunther S, Wisner DH, Cooke DT, Gold CK, Wong MS (2015) Rise in microsurgical free-flap breast reconstruction in academic medical practices. Ann Plast Surg 74(Suppl 1):S62-65. doi:10.1097/sap.0000000000000483

5. Kummerow KL, Du L, Penson DF, Shyr Y, Hooks MA (2015) Nationwide trends in mastectomy for early-stage breast cancer. JAMA surg 150(1):9-16. doi:10.1001/jamasurg.2014.2895

6. Tracy MS, Rosenberg SM, Dominici L, Partridge AH (2013) Contralateral prophylactic mastectomy in women with breast cancer: trends, predictors, and areas for future research. Breast Cancer Res Treat 140(3):447-452. doi:10.1007/s10549-013-2643-6

7. Jeevan R, Cromwell DA, Browne JP, Caddy CM, Pereira J, Sheppard C, Greenaway K, van der Meulen JH (2014) Findings of a national comparative audit of mastectomy and breast reconstruction surgery in England. J plast reconstr aesthet surg 67(10):13331344. doi:10.1016/j.bjps.2014.04.022

8. Roder D, Zorbas H, Kollias J, Pyke C, Walters D, Campbell I, Taylor C, Webster F (2013) Factors predictive of immediate breast reconstruction following mastectomy for invasive breast cancer in Australia. Breast 22(6):1220-1225. doi:10.1016/j. breast.2013.09.011

9. Rutter CE, Park HS, Killelea BK, Evans SB (2015) Growing use of mastectomy for ductal carcinoma-in situ of the breast among young women in the United States. Ann Surg Oncol 22(7):23782386. doi:10.1245/s10434-014-4334-x

10. Chen CL, Liao MN, Chen SC, Chan PL, Chen SC (2012) Body image and its predictors in breast cancer patients receiving surgery. Cancer Nurs 35(5):E10-16. doi:10.1097/NCC.0b013e3182336f8b

11. Moreira H, Canavarro MC (2010) A longitudinal study about the body image and psychosocial adjustment of breast cancer patients during the course of the disease. Eur J oncol 14(4):263-270. doi:10.1016/j.ejon.2010.04.001

12. Al-Ghazal SK, Sully L, Fallowfield L, Blamey RW (2000) The psychological impact of immediate rather than delayed breast reconstruction. Eur J Surg Oncol 26(1):17-19 
13. Rowland JH, Holland JC, Chaglassian T, Kinne D (1993) Psychological response to breast reconstruction. Expectations for and impact on postmastectomy functioning. Psychosomatics 34(3):241-250. doi:10.1016/s0033-3182(93)71886-1

14. Al-Ghazal SK, Fallowfield L, Blamey RW (2000) Comparison of psychological aspects and patient satisfaction following breast conserving surgery, simple mastectomy and breast reconstruction. Eur J Cancer 36(15):1938-1943

15. Wilkins EG, Cederna PS, Lowery JC, Davis JA, Kim HM, Roth RS, Goldfarb S, Izenberg PH, Houin HP, Shaheen KW (2000) Prospective analysis of psychosocial outcomes in breast reconstruction: one-year postoperative results from the Michigan Breast Reconstruction Outcome Study. Plast Reconstr Surg 106(5):10141025; discussion 1026-1017

16. Brennan ME, Spillane AJ (2013) Uptake and predictors of postmastectomy reconstruction in women with breast malignancysystematic review. Eur J Surg 39(6):527-541. doi:10.1016/j. ejso.2013.02.021

17. Hawley ST, Hofer TP, Janz NK, Fagerlin A, Schwartz K, Liu L, Deapen D, Morrow M, Katz SJ (2006) Correlates of between-surgeon variation in breast cancer treatments. Med Care 44(7):609616. doi:10.1097/01.mlr.0000215893.01968.f1

18. Alderman AK, Hawley ST, Waljee J, Morrow M, Katz SJ (2007) Correlates of referral practices of general surgeons to plastic surgeons for mastectomy reconstruction. Cancer 109(9):1715-1720. doi: $10.1002 /$ cncr. 22598

19. Albornoz CR, Bach PB, Mehrara BJ, Disa JJ, Pusic AL, McCarthy CM, Cordeiro PG, Matros E (2013) A paradigm shift in US breast reconstruction: increasing implant rates. Plast Reconstr Surg 131(1):15-23. doi:10.1097/PRS.0b013e3182729cde

20. Temple CL, Ross DC, Kim S, Tse R, Bettger-Hahn M, Gan BS, MacDermid J (2009) Sensibility following innervated free TRAM flap for breast reconstruction: part II. innervation improves patient-rated quality of life. Plast Reconstr Surg 124(5):14191425. doi:10.1097/PRS.0b013e3181b98963

21. Enajat M, Rozen WM, Audolfsson T, Acosta R (2009) Thermal injuries in the insensate deep inferior epigastric artery perforator flap: case series and literature review on mechanisms of injury. Microsurgery 29(3):214-217. doi:10.1002/micr.20601

22. Faulkner HR, Colwell AS, Liao EC, Winograd JM, Austen WG Jr (2016) Thermal injury to reconstructed breasts from commonly used warming devices: a risk for reconstructive failure. Plast Reconstr Surg Glob Open 4(10):e1033. doi:10.1097/ gox.0000000000001033

23. Damen TH, Timman R, Kunst EH, Gopie JP, Bresser PJ, Seynaeve C, Menke-Pluijmers MB, Mureau MA, Hofer SO, Tibben A (2010) High satisfaction rates in women after DIEP flap breast reconstruction. J plast reconstr aesthet surg 63(1):93-100. doi:10.1016/j.bjps.2008.08.019

24. Bresser PJ, Seynaeve C, Van Gool AR, Brekelmans CT, MeijersHeijboer H, van Geel AN, Menke-Pluijmers MB, Duivenvoorden HJ, Klijn JG, Tibben A (2006) Satisfaction with prophylactic mastectomy and breast reconstruction in genetically predisposed women. Plast Reconstr Surg 117(6):1675-1682. doi:10.1097/01. prs.0000217383.99038.f5; discussion 1683-1674
25. Rabin RC (2017) After mastectomies, an unexpected blow: numb new breasts. The New York Times, January 30, 2017

26. Magarakis M, Venkat R, Dellon AL, Shridharani SM, Bellamy J, Vaca EE, Jeter SC, Zoras O, Manahan MA, Rosson GD (2013) Pilot study of breast sensation after breast reconstruction: evaluating the effects of radiation therapy and perforator flap neurotization on sensory recovery. Microsurgery 33(6):421-431. doi:10.1002/micr.22124

27. Shridharani SM, Magarakis M, Stapleton SM, Basdag B, Seal SM, Rosson GD (2010) Breast sensation after breast reconstruction: a systematic review. J Reconstr Microsurg 26(5):303-310. doi:10. 1055/s-0030-1249313

28. Yap LH, Whiten SC, Forster A, Stevenson HJ (2005) Sensory recovery in the sensate free transverse rectus abdominis myocutaneous flap. Plast Reconstr Surg 115(5):1280-1288

29. Spiegel AJ, Menn ZK, Eldor L, Kaufman Y, Dellon AL (2013) Breast reinnervation: diep neurotization using the third anterior intercostal nerve. Plast Reconstr Surg Glob Open 1(8):e72. doi:10.1097/gox.0000000000000008

30. Blondeel PN (1999) The sensate free superior gluteal artery perforator (S-GAP) flap: a valuable alternative in autologous breast reconstruction. Br J Plast Surg 52(3):185-193. doi:10.1054/ bjps.1998.3032

31. Blondeel PN, Demuynck M, Mete D, Monstrey SJ, Van Landuyt K, Matton G, Vanderstraeten GG (1999) Sensory nerve repair in perforator flaps for autologous breast reconstruction: sensational or senseless? Br J Plast Surg 52(1):37-44

32. von Elm E, Altman DG, Egger M, Pocock SJ, Gotzsche PC, Vandenbroucke JP (2008) The strengthening the reporting of observational studies in epidemiology (STROBE) statement: guidelines for reporting observational studies. J Clin Epidemiol 61(4):344349. doi:10.1016/j.jclinepi.2007.11.008

33. Weinstein S (1993) Fifty years of somatosensory research: from the Semmes-Weinstein monofilaments to the Weinstein Enhanced Sensory Test. J Hand Ther 6(1):11-22; discussion 50

34. Marchac D, de Olarte G (1982) Reduction mammaplasty and correction of ptosis with a short inframammary scar. Plast Reconstr Surg 69(1):45-55

35. Spiegel AJ, Salazar-Reyes H, Izaddoost S, Khan FN (2009) A novel method for neurotization of deep inferior epigastric perforator and superficial inferior epigastric artery flaps. Plast Reconstr Surg 123(1):29e-30e. doi:10.1097/PRS.0b013e3181905564

36. Alderman AK, Chung KC (2009) Discussion. Sensibility following innervated free TRAM flap for breast reconstruction: part II. Innervation improves patient-rated quality of life. Plast Reconstr Surg 124(5):1426-1428. doi:10.1097/PRS.0b013e3181baba54

37. Wommack CC, Spiegel AJ (2016) Beyond quantitative measurement of breast reconstruction outcomes: evaluation of nipple-sparing mastectomy and the Breast-Q. Breast J 22(1):7-9. doi: $10.1111 /$ tbj. 12543

38. Pusic AL, Klassen AF, Scott AM, Klok JA, Cordeiro PG, Cano SJ (2009) Development of a new patient-reported outcome measure for breast surgery: the BREAST-Q. Plast Reconstr Surg 124(2):345-353. doi:10.1097/PRS.0b013e3181aee807 